\title{
Differentiation of ring-substituted bromoamphetamine analogs by gas chromatography-tandem mass spectrometry
}

\author{
Hiroyuki Inoue $^{1} \cdot$ Shoko Negishi $^{1,2} \cdot$ Yukiko Nakazono $^{1,2} \cdot$ Yuko T. Iwata $^{1}$ • \\ Kenji Tsujikawa $^{1}$ - Osamu Ohtsuru ${ }^{1}$ Kazuna Miyamoto ${ }^{2,3} \cdot$ Takuya Yamashita $^{3}$. \\ Fumiyo Kasuya ${ }^{3}$
}

Received: 6 June 2015/ Accepted: 8 October 2015/Published online: 14 November 2015

(C) Japanese Association of Forensic Toxicology and Springer Japan 2015

\begin{abstract}
There has been a rapid increase over the last decade in the appearance of new non-controlled psychoactive substances. Minor changes in the chemical structures of these compounds, such as the extension of an alkyl residue or replacement of a single substituent, are regularly made to avoid regulatory control, leading to the manufacture of many new potentially dangerous drugs. Bromoamphetamine analogs (bromoamphetamine [Br-AP] and bromomethamphetamine (Br-MA]) are ring-substituted amphetamines that can behave as stimulants, as well as exhibiting inhibitory activity towards monoamine oxidases in the same way as amphetamines. Gas chromatography-tandem mass spectrometry (GC-MS-MS) was used in this study to differentiate ring-substituted bromoamphetamine analogs. Free bases, trifluoroacetyl derivatives, and trimethylsilyl (TMS) derivatives of six analytes were successfully separated using DB-1ms and DB-5ms columns. Electron ionization MS-MS analysis of the TMS derivatives allowed for the differentiation of three regioisomers. TMS derivatives of 2-positional isomers provided significant product ions. The spectral patterns of 3- and 4-positional isomers were different. Chemical ionization MS-MS analysis of free bases for $[\mathrm{M}+\mathrm{H}-\mathrm{HBr}]^{+}$ions at $\mathrm{m} / \mathrm{z} 134$ and 148 allowed for differentiation of the
\end{abstract}

Hiroyuki Inoue

inoue@nrips.go.jp

1 National Research Institute of Police Science, 6-3-1 Kashiwanoha, Kashiwa 277-0882, Japan

2 Technopro, Inc. Technopro R\&D, Company, 1-15-1 Benten, Chuo-ku, Chiba 260-0045, Japan

3 Biochemical Toxicology Laboratory, Faculty of Pharmaceutical Sciences, Kobegakuin University, 1-1-3 Minatojima, Chuo-ku, Kobe 650-8586, Japan regioisomers. The spectra of 2-positional isomers contained characteristic product ions formed by dehydrogenation at $\mathrm{m} / z, 132$ and $\mathrm{m} / \mathrm{z} 146$ for 2Br-AP and 2Br-MA, respectively. The spectra of 3-positional isomers contained $\alpha$-cleaved iminium cations as the base peaks. The spectra of 4-positional isomers showed a tropylium cation at $\mathrm{m} / \mathrm{z}$ 91 as the base peak. These results demonstrate that GCMS-MS can be used for the differentiation of regioisomeric $\mathrm{Br}-\mathrm{AP}$ analogs in forensic practice.

Keywords Bromoamphetamine analogs $\cdot$ Regioisomeric differentiation - GC-MS-MS · Electron ionization .

Chemical ionization

\section{Introduction}

Over the last decade, several types of new psychoactive substances have appeared across the globe [1-3]. Because many of these new substances represent slight structural variations from known controlled drugs, there is an urgent need for analytical methods capable of structural differentiation of these new drugs to enable forensic laboratories to exert regulatory control over these agents and to prevent drug abuse [4-12].

Studies have reported that the affinity of 4-bromoamphetamine (4Br-AP) for the $5-\mathrm{HT}_{1 \mathrm{C}}$ receptor is higher than that of amphetamine and lower than that of lysergic acid diethylamide (LSD), and research has also suggested that the affinity of $4 \mathrm{Br}-\mathrm{AP}$ for the $5-\mathrm{HT}_{2}$ receptor is similar to its affinity for the 5- $\mathrm{HT}_{1 \mathrm{C}}$ receptor [13]. $4 \mathrm{Br}-\mathrm{AP}$ has the ability to cause mydriasis [14] and to deplete brain 5-hydroxyindoleacetic acid and serotonin levels in the same way as 4-fluoroamphetamine and 4-chloroamphetamine [15]. Furthermore, 4Br-AP has been reported to have a 
half-life of $5.7 \mathrm{~h}$ in the rat brain, which is longer than that of amphetamine, 4-fluoroamphetamine, and 4-chloroamphetamine. It has also been shown to produced neurotoxic reactions in cell bodies located within the $\mathrm{B} 9$ region of the raphe nucleus, while 4-fluoroamphetamine has demonstrated no detectable neurotoxic effect $[16,17]$. Moreover, animals treated with 4-bromomethamphetamine (4Br-MA) have reportedly exhibited high levels of excitement, salivation, and hyperthermia [18]. Symptoms of head shaking and aggressive behavior were also more marked with $4 \mathrm{Br}$ MA than with amphetamine or methamphetamine. $4 \mathrm{Br}$ MA has also been reported to cause insomnia [19], and has about one-tenth of the activity of LSD in terms of its ability to prolong a conditioned escape reaction [20, 21].

In the United Kingdom, 4Br-AP was detected in tablets containing amphetamine in March 2014 [22]. Although bromoamphetamine analogs have not been detected to date in forensic samples in Japan, there is a strong possibility that these drugs could be abused as alternative unregulated psychoactive substances.

Gas chromatography-mass spectrometry (GC-MS) is generally used for the identification of drugs, as it is usually supported by an extensive electron ionization-mass spectrometry (EI-MS) database. In this study, GC-MS and GCtandem mass spectrometry (GC-MS-MS) with EI and chemical ionization $(\mathrm{CI})$ were used to differentiate the regioisomers of bromoamphetamine analogs (Br-APs and Br-MAs, Fig. 1).

\section{Materials and methods}

\section{Chemicals}

2-Bromophenylacetone, 3-bromophenylacetone, and $\mathrm{N}, \mathrm{O}$ bis(trimethylsilyl)trifluoroacetamide (BSTFA) containing

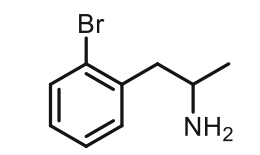

1) 2-Bromoamphetamine (2Br-AP)

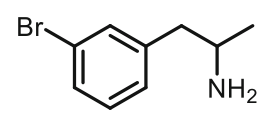

2) 3-Bromoamphetamine (3Br-AP)

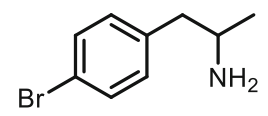

3) 4-Bromoamphetamine (4Br-AP)

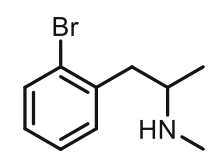

4) 2-Bromomethamphetamine (2Br-MA)

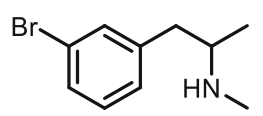

5) 3-Bromomethamphetamine (3Br-MA)

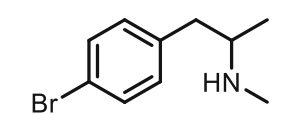

6) 4-Bromomethamphetamine $(4 \mathrm{Br}-\mathrm{MA})$
Fig. 1 Chemical structures of regioisomers of bromoamphetamine analogs
$1 \%$ trimethylchlorosilane (TMCS) were purchased from Sigma-Aldrich (St. Louis, MO, USA), and 4-bromophenylacetone was obtained from Alfa Aesar (Heysham, UK). Methylamine hydrochloride and sodium cyanoborohydride were purchased from Tokyo Chemical Industry (Tokyo, Japan), and trifluoroacetic anhydride (TFAA) was purchased from Wako Pure Chemical Industries (Osaka, Japan). All other chemicals were of analytical grade.

\section{Synthesis of bromoamphetamines}

A solution of bromophenylacetone and ammonium acetate or methylamine hydrochloride (5 equiv.) in methanol was stirred at room temperature for $1 \mathrm{~h}$. The mixture was then cooled to $0{ }^{\circ} \mathrm{C}$ and treated with sodium cyanoborohydride (0.4 equiv) (Fig. 2). Upon completion of the reaction, the $\mathrm{pH}$ of the mixture was adjusted to 12 by the addition of a $10 \%$ potassium hydroxide aqueous solution, and the resulting mixture was extracted with diethyl ether, washed with water, and dried over sodium sulfate. The solvent was then evaporated under reduced pressure to give the crude product as a residue, which was purified by column chromatography over silica gel eluting with a 10:1 (v/v) mixture of chloroform and methanol.

The chemical structures were confirmed by proton nuclear magnetic resonance $\left({ }^{1} \mathrm{H}\right.$ NMR) spectroscopy (resolution: $400 \mathrm{MHz}$ ). ${ }^{1} \mathrm{H} \mathrm{NMR}$ spectra were recorded on a JNM-ECP 400 spectrometer (JEOL Ltd., Akishima, Japan) at room temperature using deuterated chloroform $\left(\mathrm{CDCl}_{3}\right)$ as a solvent, with tetramethylsilane as an internal standard. The ${ }^{1} \mathrm{H}$ NMR data for each synthesized compound are summarized below.

2Br-AP; ${ }^{1} \mathrm{H}$ NMR $\left(\mathrm{CDCl}_{3}\right) \delta: 7.55(1 \mathrm{H}, \mathrm{d}, J=8.4 \mathrm{~Hz})$, 7.25-7.23 (2H, m), 7.11-7.09 (1H, m), 3.32-3.25 (1H, m), $2.86(1 \mathrm{H}, \mathrm{dd}, J=13.2,5.6 \mathrm{~Hz}), 2.70(1 \mathrm{H}, \mathrm{dd}, J=13.2$, $8.0 \mathrm{~Hz}), 1.16(3 \mathrm{H}, \mathrm{d}, J=6.4 \mathrm{~Hz})$.

3Br-AP; ${ }^{1} \mathrm{H}$ NMR $\left(\mathrm{CDCl}_{3}\right) \delta: 7.36-7.34(2 \mathrm{H}, \mathrm{m})$, 7.19-7.11 (2H, m), 3.16-3.13 (1H, m), $2.67(1 \mathrm{H}, \mathrm{dd}$, $J=13.2,5.6 \mathrm{~Hz}), 2.50(1 \mathrm{H}, \mathrm{dd}, J=13.2,8.0 \mathrm{~Hz}), 1.12$ $(3 \mathrm{H}, \mathrm{d}, J=6.4 \mathrm{~Hz})$.

4Br-AP; ${ }^{1} \mathrm{H}$ NMR $\left(\mathrm{CDCl}_{3}\right) \quad \delta: 7.43-7.41 \quad(2 \mathrm{H}, \mathrm{m})$, 7.08-7.06 $(2 \mathrm{H}, \mathrm{m}), 3.16-3.12(1 \mathrm{H}, \mathrm{m}), 2.66(1 \mathrm{H}, \mathrm{dd}$, $J=13.2,5.6 \mathrm{~Hz}), 2.49(1 \mathrm{H}, \mathrm{dd}, J=13.2,8.0 \mathrm{~Hz}), 1.11$ $(3 \mathrm{H}, \mathrm{d}, J=6.4 \mathrm{~Hz})$.

2Br-MA; ${ }^{1} \mathrm{H}$ NMR $\left(\mathrm{CDCl}_{3}\right) \delta: 7.56-7.54(1 \mathrm{H}, \mathrm{m})$, 7.25-7.22 (2H, m), 7.10-7.08 (1H, m), 2.98-2.91 (2H, m), 2.72-2.66 (1H, m), $2.45(3 \mathrm{H}, \mathrm{s}), 1.08(3 \mathrm{H}, \mathrm{d}, J=6.4 \mathrm{~Hz})$.

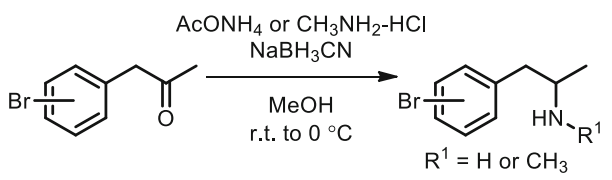

Fig. 2 Synthesis of regioisomers of bromoamphetamine analogs 
3Br-MA; ${ }^{1} \mathrm{H}$ NMR $\left(\mathrm{CDCl}_{3}\right) \delta: 7.36-7.34 \quad(2 \mathrm{H}, \mathrm{m})$, 7.16-7.10 (2H, m), 2.83-2.78 (1H, m), 2.75-2.71 (1H, m), $2.57(1 \mathrm{H}, \mathrm{dd}, J=13.2,6.0 \mathrm{~Hz}), 2.42(3 \mathrm{H}, \mathrm{s}), 1.06(3 \mathrm{H}, \mathrm{d}$, $J=6.4 \mathrm{~Hz})$.

4Br-MA; ${ }^{1} \mathrm{H}$ NMR $\left(\mathrm{CDCl}_{3}\right) \delta: 7.43-7.40(2 \mathrm{H}, \mathrm{m})$, 7.07-7.05 (2H, m), 2.80-2.75 (1H, m), 2.71-2.67 (1H, m), $2.56(1 \mathrm{H}, \mathrm{dd}, J=13.2,6.4 \mathrm{~Hz}), 2.40(3 \mathrm{H}, \mathrm{s}), 1.05(3 \mathrm{H}, \mathrm{d}$, $J=6.4 \mathrm{~Hz})$.

\section{Preparation of sample solution}

Standard stock solutions of all six analytes as corresponding hydrochloride salts were prepared in distilled water at a concentration of $1.0 \mathrm{mg} / \mathrm{ml}$. The solutions were further diluted with distilled water to reach the appropriate concentrations required for analysis.

\section{Extraction procedure}

One-milliliter samples of $0.5 \mathrm{mg} / \mathrm{ml}$ aqueous solution of the hydrochloride salts of the bromoamphetamine analogs were alkalinized by the addition of $20 \mu \mathrm{l}$ of $2 \mathrm{M}$ aqueous sodium hydroxide solution, and extracted with $1 \mathrm{ml}$ of ethyl acetate for $3 \mathrm{~min}$. The organic layer was then centrifuged, and a portion of the extract was collected and diluted ten times before analysis by GC-MS.

\section{Trifluoroacetylation of analytes}

A forty-microliter aliquot of each extracted sample with ethyl acetate was evaporated to dryness under a gentle stream of nitrogen. The residue was dissolved in $400 \mu \mathrm{l}$ of a 1:1 (v/v) mixture of ethyl acetate and TFAA, and the resulting mixture was heated at $50{ }^{\circ} \mathrm{C}$ for $15 \mathrm{~min}$. After cooling to room temperature, the mixture was evaporated to dryness under a gentle stream of nitrogen, and the resulting residue was dissolved in $1 \mathrm{ml}$ of ethyl acetate before analysis by GC-MS.

\section{Silylation of analytes}

A ten-microliter aliquot of each extracted sample with ethyl acetate was evaporated to dryness under a gentle stream of nitrogen. The residue was dissolved in $200 \mu \mathrm{l}$ of a $1: 1(\mathrm{v} / \mathrm{v})$ mixture of acetonitrile and BSTFA containing $1 \%$ TMCS, and the resulting mixture was heated at $80{ }^{\circ} \mathrm{C}$ for $30 \mathrm{~min}$. After cooling to room temperature, the mixture was subjected to GC-MS analysis.

\section{GC-MS conditions}

GC-MS analysis was performed on a 7000 triple quadrupole GC-MS system (Agilent, Santa Clara, CA, USA) equipped with a DB-1ms, DB-5ms or DB- $17 \mathrm{~ms}$ capillary column $(30 \mathrm{~m} \times 0.25 \mathrm{~mm}$ I.D., film thickness $0.25 \mu \mathrm{m}$; Agilent J\&W, Folsom, CA, USA). The oven temperature was maintained at $80{ }^{\circ} \mathrm{C}$ for $1 \mathrm{~min}$ following the injection of each sample and then increased to $300{ }^{\circ} \mathrm{C}$ at a rate of $15^{\circ} \mathrm{C} / \mathrm{min}$. The injection port and interface temperature were set at $250{ }^{\circ} \mathrm{C}$. Helium was used as the carrier gas at a flow rate of $1.0 \mathrm{ml} / \mathrm{min}$. One microliter of sample solution was injected in splitless mode.

For EI mode, the ionization energy was $70 \mathrm{eV}$, the ion source temperature was $230{ }^{\circ} \mathrm{C}$, and the scan mass range was $m / z$ 40-400.

For CI mode, the ionization energy was $70 \mathrm{eV}$, the ion source temperature was $250{ }^{\circ} \mathrm{C}$, and the scan mass range was $m / z$ 43-400. Methane was used as a reactant gas.

\section{Results and discussion}

\section{Gas chromatography}

Figure 3 shows total ion current chromatograms of free bases, trifluoroacetyl (TFA) derivatives, and trimethylsilyl (TMS) derivatives of bromoamphetamine analogs. The elution order of the isomers was 2-positional isomer $>3$ positional isomer $>4$-positional isomer for $\mathrm{Br}$-APs and $\mathrm{Br}$ MAs across all three columns. On the DB-1ms and DB$5 \mathrm{~ms}$ columns, all three forms of bromoamphetamine analogs, including free bases and TFA and TMS derivatives, were completely separated (Fig. 3a, b). The DB-17ms column failed to separate free bases of $4 \mathrm{Br}-\mathrm{AP}$ and $2 \mathrm{Br}$ MA (Fig. 3c).

\section{Electron ionization-mass spectrometry}

The EI mass spectra of free bases of bromoamphetamine analogs are shown in Fig. 4. The mass spectra were very similar among the three regioisomers. Bromoamphetamine analogs gave a major fragment ion at $m / z 44$ or 58 by $\alpha$ cleavage. Although debromination has been reported as a characteristic fragmentation of 2-brominated dimethoxyamphetamines [23, 24], the corresponding debrominated ions were not detected in the spectra of $2 \mathrm{Br}$ AP and 2Br-MA or the spectra of the 3- and 4-positional isomers. The corresponding TFA and TMS derivatives also gave very similar mass spectra for the different regioisomers (data not shown). The spectra of free bases and TFA derivatives of $4 \mathrm{Br}-\mathrm{AP}$ and $4 \mathrm{Br}-\mathrm{MA}$ were in good agreement with those previously reported in the literature [25, 26]. Because the spectra of the three different analogs gave very little information about the position of the bromine atom on the aromatic ring, it was difficult to differentiate bromoamphetamine analogs using EI-MS. 
(a) DB-1ms

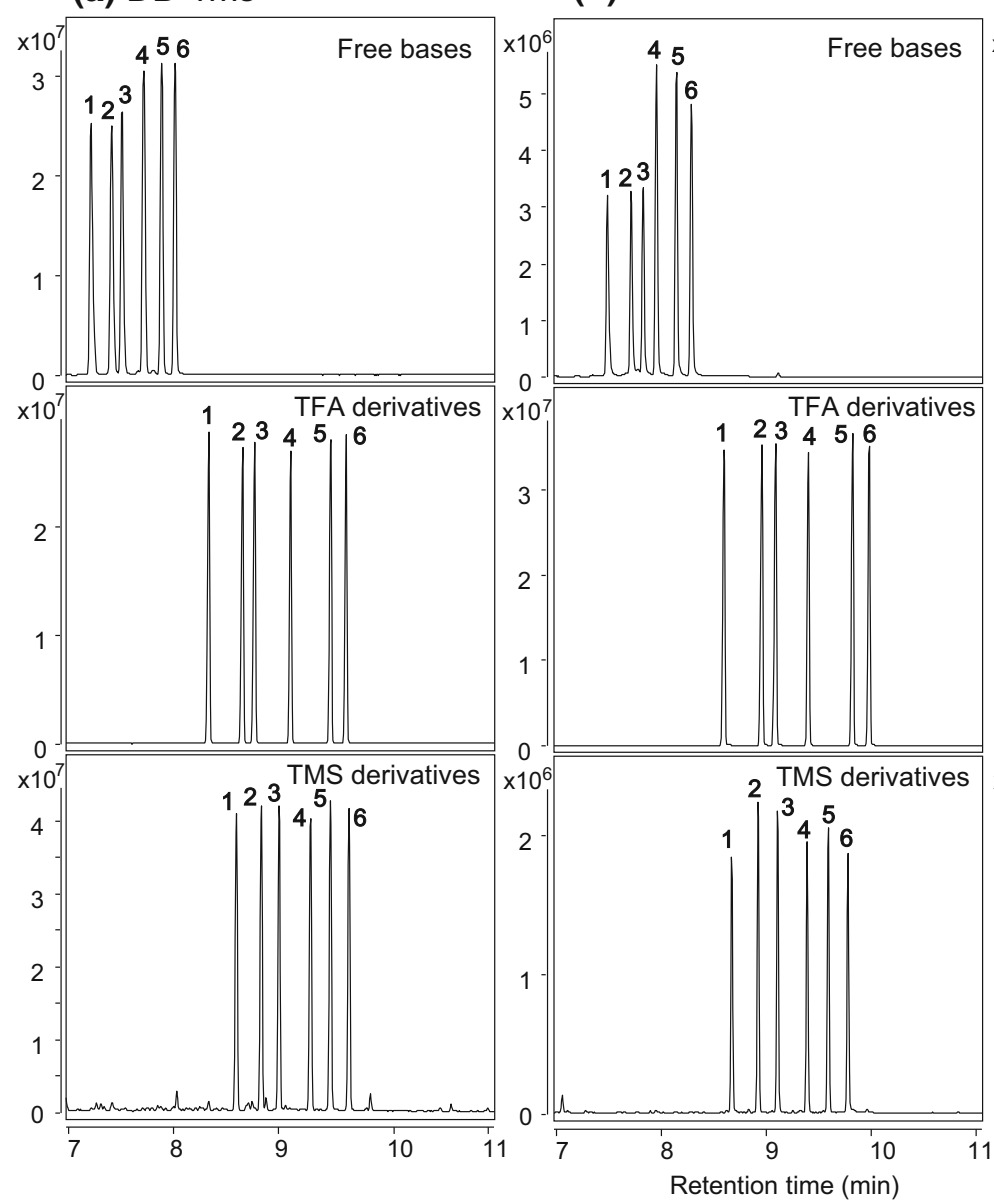

(b) DB-5ms

Fig. 3 Total ion current chromatograms for free bases, trifluoroacetyl (TFA) derivatives, and trimethylsilyl (TMS) derivatives of bromoamphetamine analogs. The compound names are the same as those in Fig. 1

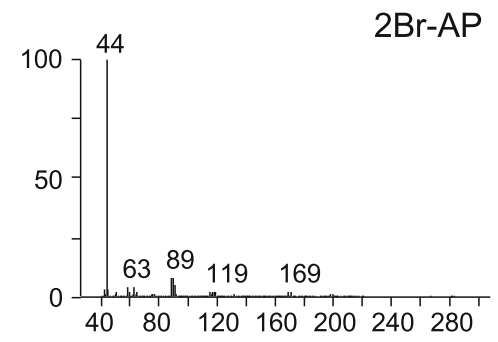

2Br-MA

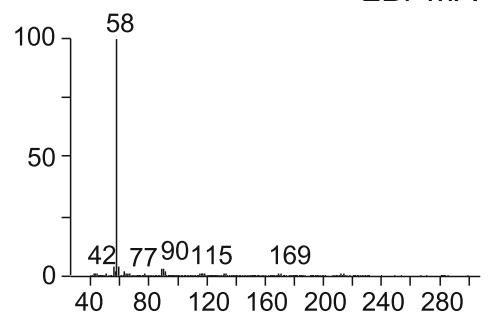

(c) $\mathrm{DB}-17 \mathrm{~ms}$

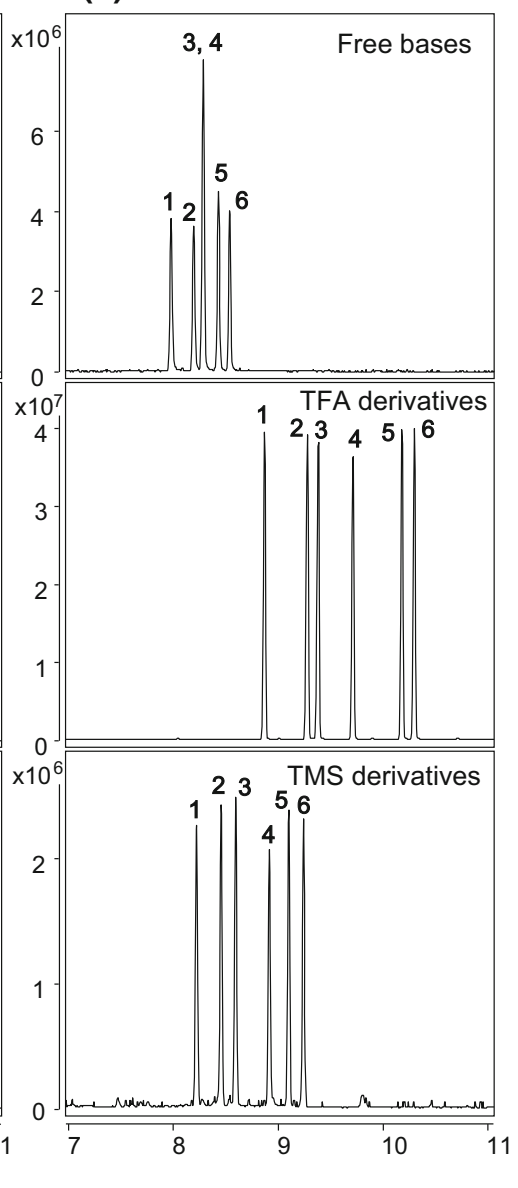

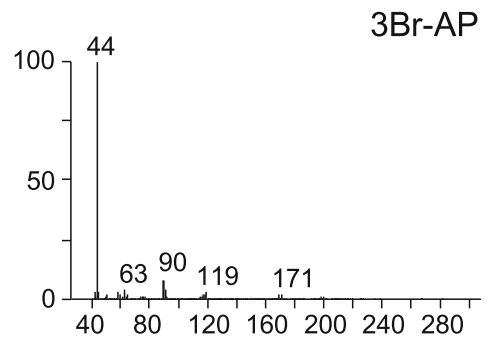
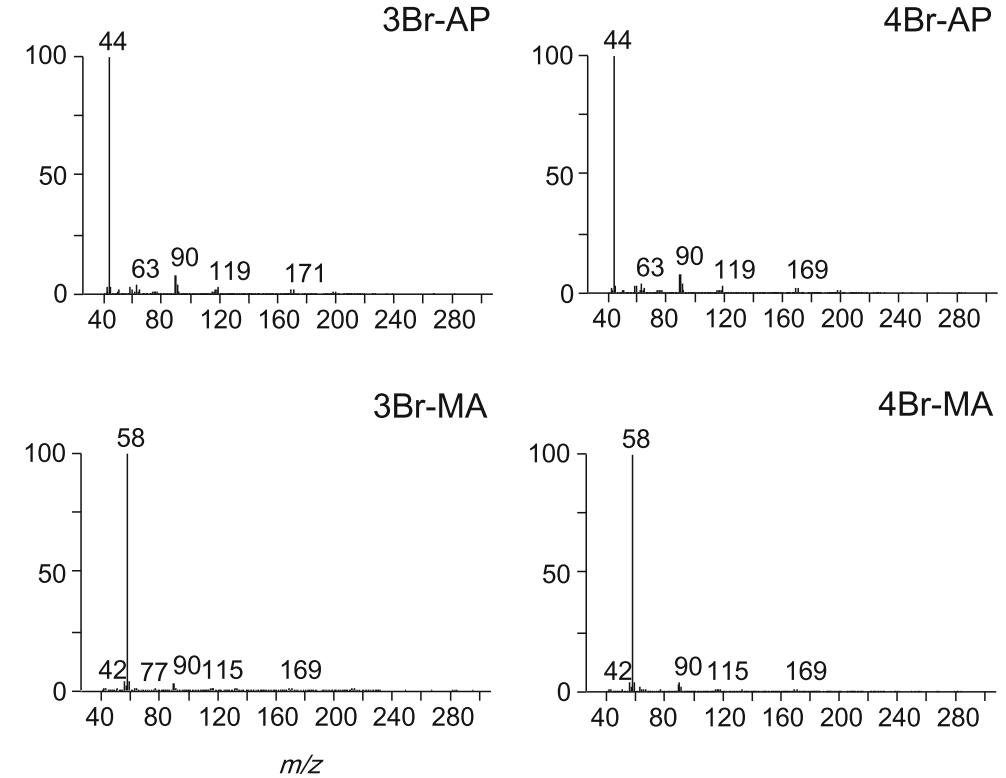

Fig. 4 Electron ionization (EI) mass spectra for free bases of bromoamphetamine analogs. Monoisotopic mass: 213 for Br-APs, 227 for Br-MAs 
EI-MS-MS was applied with a collision energy of $60 \mathrm{eV}$ to allow for the differentiation of bromoamphetamine analogs. TMS derivatives of 2-positional isomers provided significant product ions at $\mathrm{m} / \mathrm{z}, 190$ and 147 for $2 \mathrm{Br}-\mathrm{AP}$ and $2 \mathrm{Br}-\mathrm{MA}$, respectively (Fig. 5). The ion at $\mathrm{m} / \mathrm{z} 190$ was attributed to the desorption of hydrogen bromide from the precursor ion $\left[\mathrm{M}-\mathrm{CH}_{3}\right]^{+}$, whereas the ion at $\mathrm{m} / z 147$ was most likely produced by the desorption of $\left[\mathrm{BrSi}\left(\mathrm{CH}_{3}\right)_{2}\right] \cdot$ from the precursor ion. TMS derivatives of $3 \mathrm{Br}-\mathrm{AP}$ and 4Br-AP differed in their ratios of $\mathrm{m} / \mathrm{z} 59,73$ and 100 in the product ion spectra. TMS derivatives of $3 \mathrm{Br}-$ MA provided a specific product ion at $\mathrm{m} / \mathrm{z}$ 102. The ratios of the product ions were highly reproducible, with less than $5 \%$ relative standard deviation. EI-MS-MS analysis of the TMS derivatives allowed for the differentiation of the three regioisomers.

For free bases of bromoamphetamine analogs, only the characteristic product ion representing 3Br-MA $(\mathrm{m} / \mathrm{z}, 104)$ was observed from the precursor ion $\left[\mathrm{M}-\mathrm{CH}_{3}\right]^{+}$at $m / z 212$ (data not shown). TFA derivatives of bromoamphetamine analogs were almost equivalent (data not shown), and it was difficult to differentiate the three regioisomers of TFA derivatives based on their EI product ion spectra.

\section{Chemical ionization-mass spectrometry}

The CI mass spectra for free bases of bromoamphetamine analogs are shown in Fig. 6. CI-MS gave $[\mathrm{M}+\mathrm{H}]^{+}$ions at $m / z 214$ and 228 for Br-APs and Br-MAs, respectively, which contained the isotope ions of bromine as the main ions. Free bases of bromoamphetamine analogs also showed $[\mathrm{M}+\mathrm{H}-\mathrm{HBr}]^{+}$ions in the mass spectra of all six analytes. Among all TFA and TMS derivatives of bromoamphetamine analogs, only the TMS derivative of $2 \mathrm{Br}$ AP showed a characteristic $[\mathrm{M}+\mathrm{H}-\mathrm{HBr}]^{+}$ion at $m / z 206$ (data not shown).

CI-MS-MS was used to allow for the differentiation of the six analytes with a variety of different collision energies. Tandem MS analysis of free bases for $[\mathrm{M}+\mathrm{H}-\mathrm{HBr}]^{+}$ ions at $m / z 134$ and 148 allowed the differentiation of the regioisomers (Fig. 7). The spectra of 2-positional isomers contained characteristic product ions at $\mathrm{m} / \mathrm{z} 132$ and $\mathrm{m} / \mathrm{z}$ 146 for $2 \mathrm{Br}-\mathrm{AP}$ and $2 \mathrm{Br}-\mathrm{MA}$, respectively. The ions were formed by the dehydrogenation of 2Br-AP and 2Br-MA with $[\mathrm{M}+\mathrm{H}-\mathrm{HBr}]^{+}$appearing as a base peak without any of the $\alpha$-cleaved iminium cation at $m / z \quad 44$ and 58, respectively. The spectrum of $2 \mathrm{Br}-\mathrm{AP}$ had a specific ion at $m / z 106$ derived from an amine tropylium cation, which was previously reported by Westphal et al. [27] for fluoroamphetamines and by Negishi et al. [28] for chloroamphetamines. The spectra of 3-positional isomers contained $\alpha$-cleaved iminium cations at $m / z, 44$ and 58 as the base peaks, and the spectra of 4-positional isomers showed a tropylium cation at $\mathrm{m} / \mathrm{z}, 91$ as the base peak. Their ratios of the product ions were highly reproducible, with less than $5 \%$ relative standard deviation. These CI-MS-MS
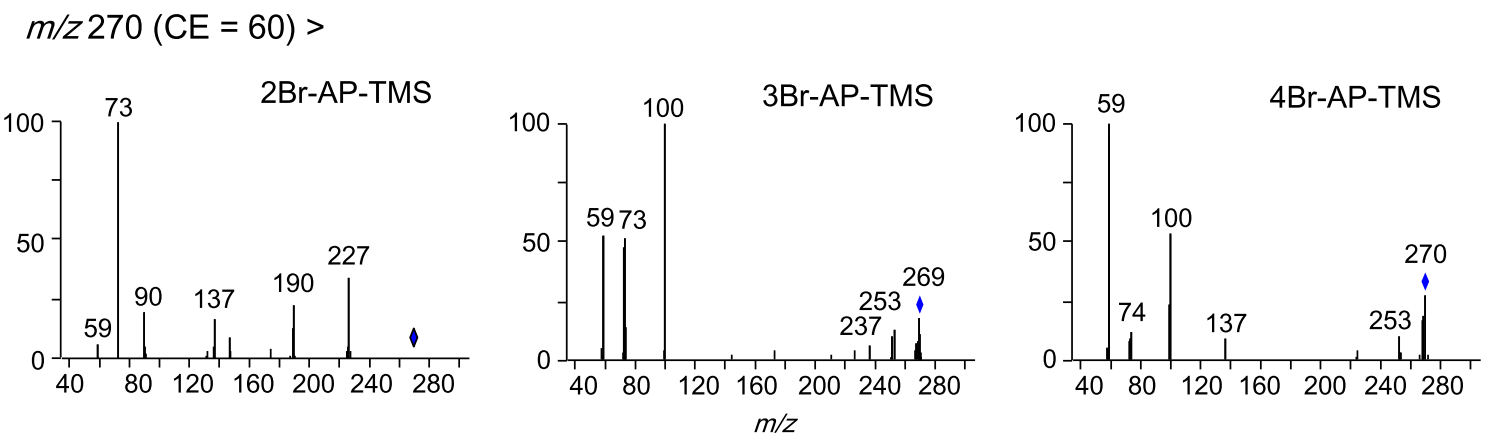

$m / z 284(\mathrm{CE}=60)>$
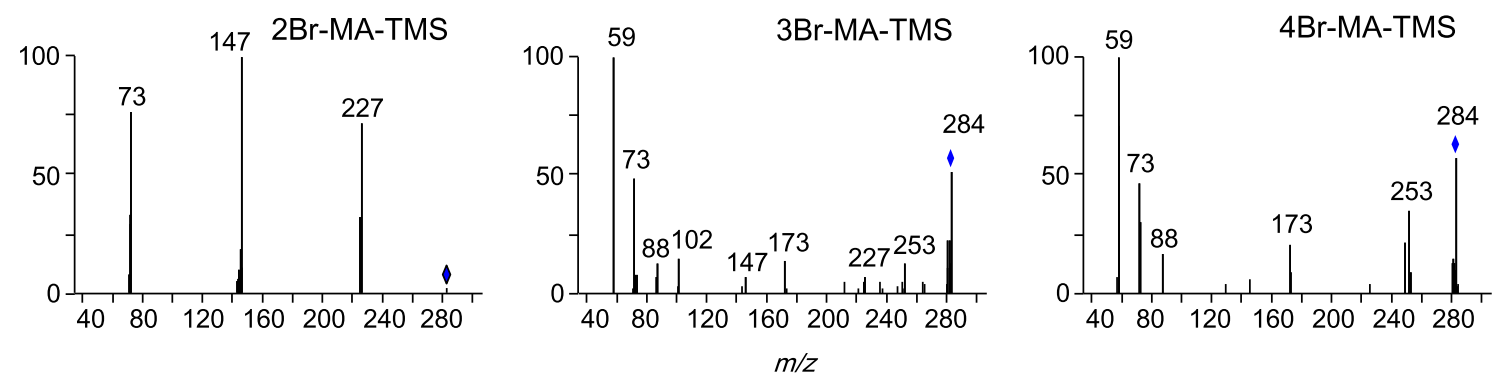

Fig. 5 Product ion spectra for TMS derivatives of bromoamphetamines (Br-Aps) (precursor ions at $\mathrm{m} / z \quad 270 \quad\left[\mathrm{M}-\mathrm{CH}_{3}\right]^{+}$) and bromomethamphetamines (Br-MAs) (precursor ions at $\mathrm{m} / \mathrm{z} 284$ [M-
$\left.\mathrm{CH}_{3}\right]^{+}$) under EI-tandem mass spectrometry (MS). Monoisotopic mass: 285 for Br-APs-TMS, 299 for Br-MAs-TMS 

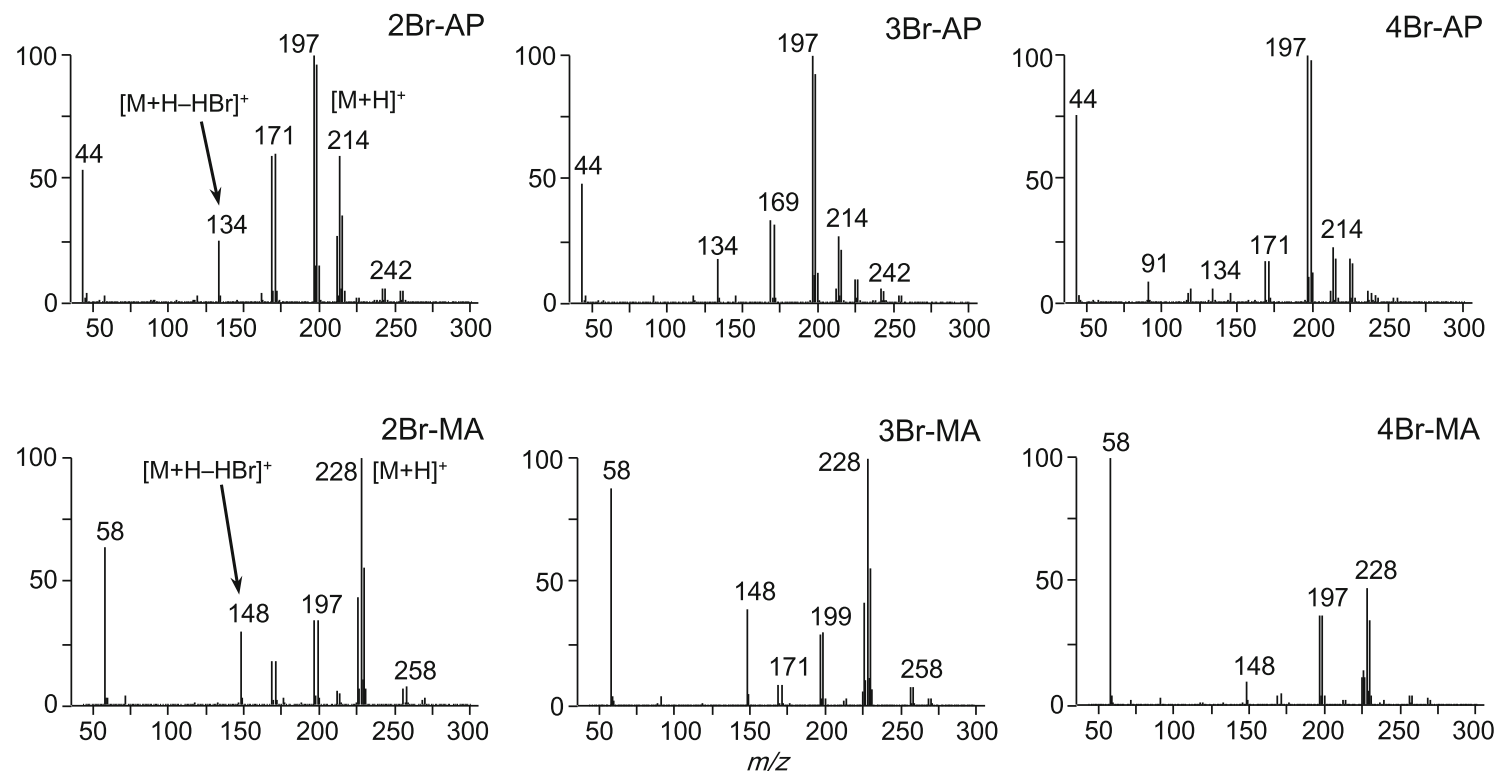

Fig. 6 Chemical ionization (CI) mass spectra for free bases of bromoamphetamine analogs
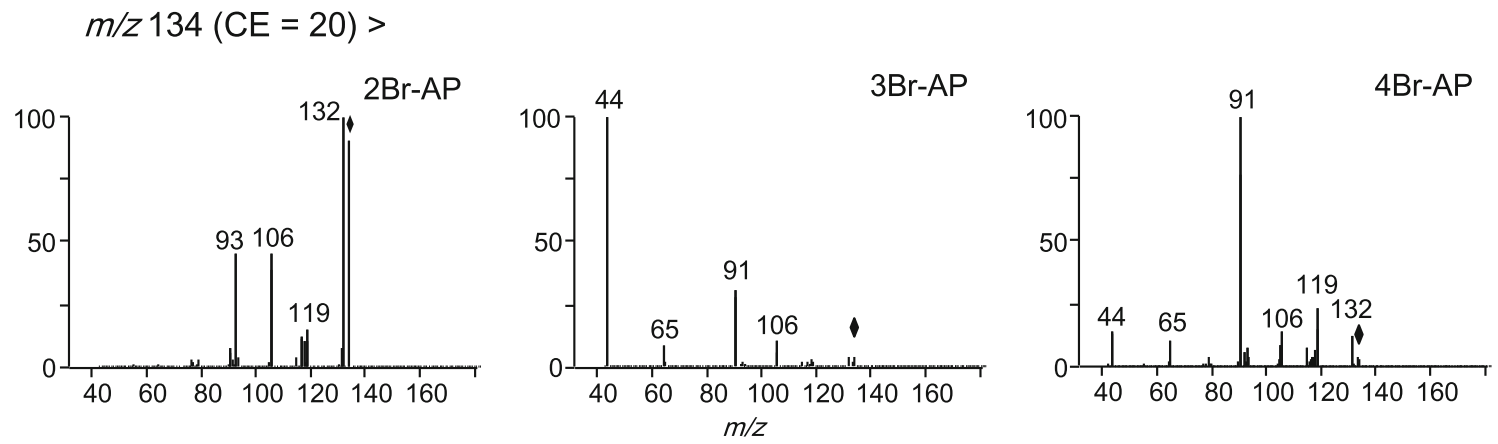

$m / z 148(C E=20)>$
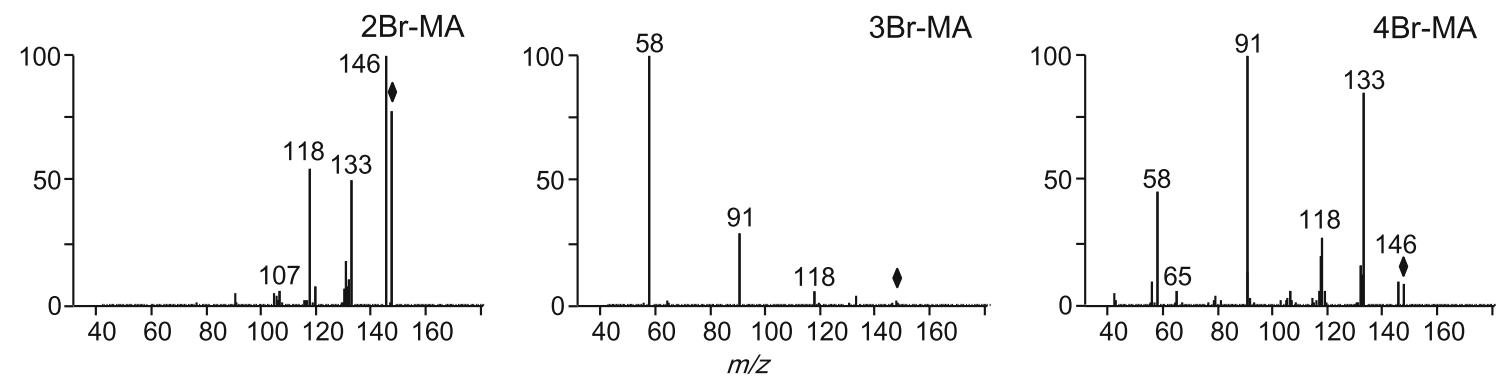

Fig. 7 Product ion spectra for free bases of Br-APs (precursor ions at $m / z, 134[\mathrm{M}+\mathrm{H}-\mathrm{HBr}]^{+}$) and Br-MAs (precursor ions at $m / z, 148[\mathrm{M}+\mathrm{H}-$ $\mathrm{HBr}]^{+}$) under CI tandem MS

fragmentation patterns were consistent with those previously reported $[27,28]$. The original regioisomeric structural information of the bromine atom position is preserved during the $\mathrm{HBr}$ loss reaction, which leads to a variation of the product ion spectra depending on the type of the bromine position. This preservation of the 3- and 4-substitution pattern information in the $\mathrm{HBr}$ loss reaction from $\mathrm{m} / \mathrm{z}$.
134 and 148 was explained by anchimeric assistance of the amino group building chelate-like intermediates with metaand para-cyclophane structures [27].

The product ion spectra of TMS derivatives of 2-positional isomers were clearly different from those of 3-and 4- positional isomers (Fig. 8). The 2-positional isomers showed fragment-rich spectra with a base peak ion at $\mathrm{m} / \mathrm{z}$ 

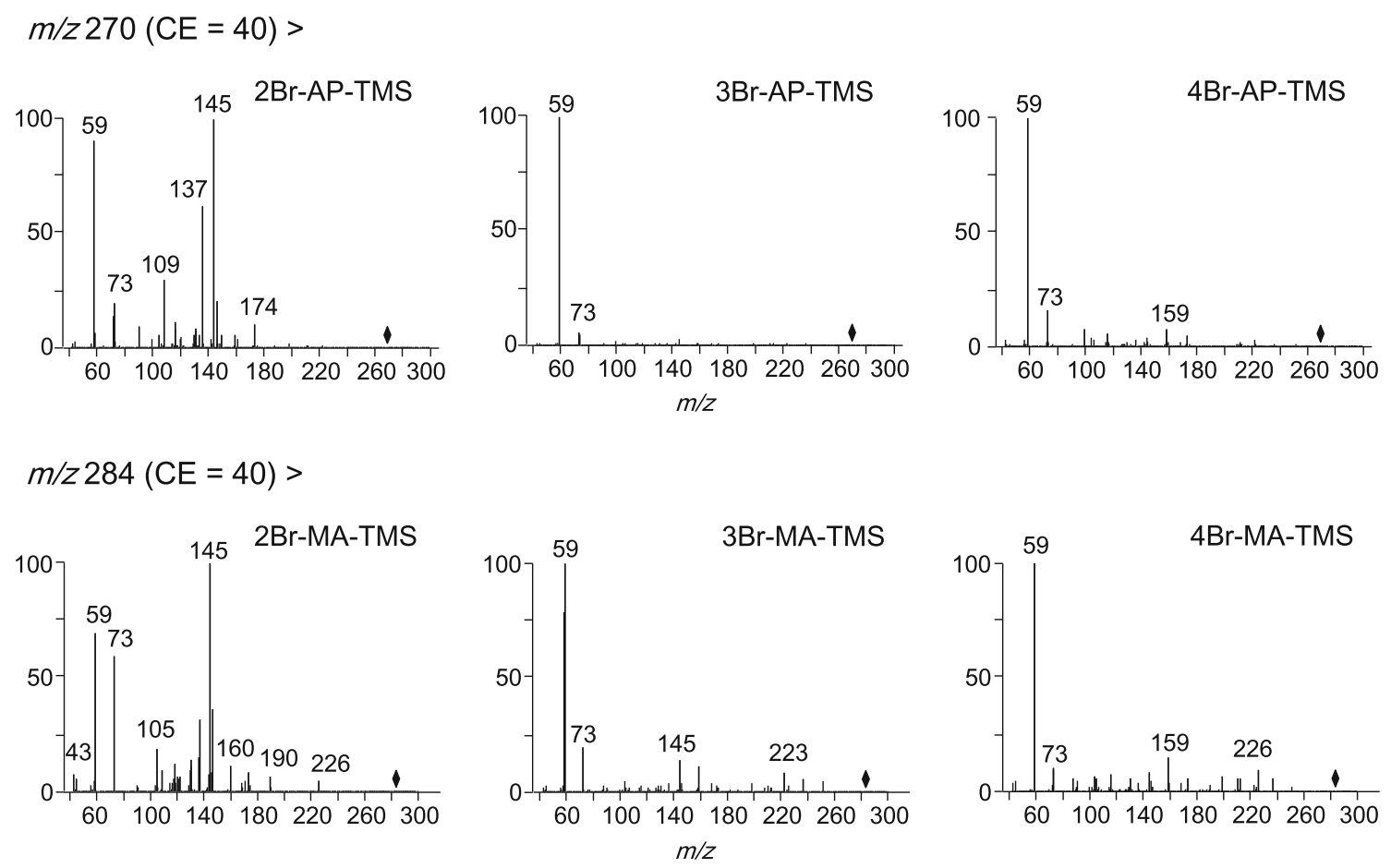

Fig. 8 Product ion spectra for TMS derivatives of Br-APs (precursor ions at $m / z, 270\left[\mathrm{M}-\mathrm{CH}_{3}\right]^{+}$) and Br-MAs (precursor ions at $m / z$, $284[\mathrm{M}-$ $\left.\mathrm{CH}_{3}\right]^{+}$) under CI tandem MS

145. The spectra of 3-positional isomers were similar to those of 4-positional isomers. Tandem MS analysis of the protonated molecules of TFA derivatives $(\mathrm{m} / \mathrm{z}, 310$ for BrAPs-TFA and $m / z, 324$ for Br-MAs-TFA) gave the same product ions at $m / z$ 169, which corresponded to the bromobenzyl ions, and $\mathrm{m} / \mathrm{z} 117$, which corresponded to the debromination of the substrate after a McLafferty rearrangement. Although the ratios of these ions were slightly different among the three isomers, differentiation between them was difficult (data not shown). These results therefore demonstrate that the analysis of free bases of bromoamphetamine analogs by CI-MS-MS gave positional information about the bromo group on the aromatic ring.

\section{Conclusions}

We have successfully differentiated a series of ring-substituted bromoamphetamine analogs using GC-MS-MS. Free bases, TFA derivatives, and TMS derivatives of six bromoamphetamine analogs were successfully separated using DB-1ms and DB-5ms columns.

EI-MS-MS analysis of the TMS derivatives allowed for the differentiation of three regioisomers. TMS derivatives of 2-positional isomers provided significant product ions at $m / z 190$ and 147 for 2Br-AP and 2Br-MA, respectively. Those of $3 \mathrm{Br}-\mathrm{AP}$ and $4 \mathrm{Br}-\mathrm{AP}$ were different in their ratios of $m / z 59,73$ and 100 in the product ion spectra. Those of $3 \mathrm{Br}-\mathrm{MA}$ provided a specific product ion at $m / z$ 102. CI-MS-MS analysis of free bases for [M+H$\mathrm{HBr}]^{+}$ions at $m / z, 134$ and 148 allowed for the differentiation of the regioisomers. The spectra of 2-positional isomers contained characteristic product ions formed by dehydrogenation at $m / z \quad 132$ and $m / z, 146$ for 2Br-AP and 2Br-MA, respectively. The spectra of 3-positional isomers contained the $\alpha$-cleaved iminium cations as the base peaks. The spectra of 4-positional isomers showed a tropylium cation at $m / z, 91$ as the base peak. These results demonstrate that GC-MS-MS can be used for the differentiation of regioisomeric $\mathrm{Br}-\mathrm{AP}$ analogs in forensic practice.

Acknowledgments This work was supported in part by the R\&D Program for the Implementation of Anti-Crime and Anti-Terrorism Technologies for a Safe and Secure Society and Funds for the Integrated Promotion of Social System Reform and Research and Development from the Ministry of Education, Culture, Sports, Science and Technology of Japan.

\section{Compliance with ethical standards}

Conflict of interest There are no financial or other considerations that could lead to a conflict of interest in relation to this study.

Ethical approval This article does not contain any studies with human participants or animals performed by any of the authors. 


\section{References}

1. EMCDDA-Europol 2013 Annual Report on the implementation of Council Decision 2005/387/JHA. (http://www.emcdda.europa. eu/publications/implementation-reports/2013). Accessed 22 Jan 2015

2. World drug report 2014. (http://www.unodc.org/documents/ wdr2014/World_Drug_Report_2014_web.pdf). Accessed 22 Jan 2015

3. King LA (2014) New phenethylamines in Europe. Drug Test Analysis 6:808-818

4. Awad T, Belal T, DeRuiter J, Kramer K, Clark CR (2009) Comparison of GC-MS and GC-IRD methods for the differentiation of methamphetamine and regioisomeric substances. Forensic Sci Int 185:67-77

5. Maher HM, Awas T, DeRuiter J, Kramer K, Clark CR (2012) GC-MS and GC-IRD studies on dimethoxyphenethylamines (DMPEA): regioisomers related to 2,5-DMPEA. J Chromatogr Sci 50:1-9

6. Pirisi MA, Nieddu M, Burrai L, Carta A, Briguglio I, Baralla E, Demontis MP, Varoni MV, Boatto G (2013) An LC-MS-MS method for quantitative analysis of six trimethoxyamphetamine designer drugs in rat plasma, and its application to a pharmacokinetic study. Forensic Toxicol 31:197-203

7. Nakazono Y, Tsujikawa K, Kuwayama K, Kanamori T, Iwata YT, Miyamoto K, Kasuya F, Inoue H (2013) Differentiation of regioisomeric fluoroamphetamine analogs by gas chromatography-mass spectrometry and liquid chromatography-tandem mass spectrometry. Forensic Toxicol 31:241-250

8. Zaitsu K, Miyagawa H, Sakamoto Y, Matsuta S, Tsuboi K, Nishioka H, Katagi M, Sato T, Tatsuno M, Tsuchihashi H, Suzuki $\mathrm{K}$, Ishii A (2013) Mass spectrometric differentiation of the isomers of mono-methoxyethylamphetamines and mono-methoxydimethylamphetamines by GC-EI-MS-MS. Forensic Toxicol 31:292-300

9. Nakazono Y, Tsujikawa K, Kuwayama K, Kanamori T, Iwata YT, Miyamoto K, Kasuya F, Inoue H (2014) Simultaneous determination of tryptamine analogs in designer drugs using gas chromatography-mass spectrometry and liquid chromatographytandem mass spectrometry. Forensic Toxicol 32:154-161

10. Negishi S, Nakazono Y, Tsujikawa K, Kuwayama K, Kanamori T, Iwata YT, Miyamoto K, Kasuya F, Inoue H (2014) Differentiation of regioisomeric methylamphetamines by GC-MS. Jpn J Forensic Sci Tech 19:111-1197 (in Japanese)

11. Kusano M, Zaitsu K, Nakayama H, Nakajima J, Hisatsune K, Moriyasu T, Matsuta S, Katagi M, Tsuchihashi H, Ishii A (2015) Positional isomer differentiation of synthetic cannabinoid JWH081 by GC-MS/MS. J Mass Spectrom 50:586-591

12. Thaxton A, Belal TS, Smith F, DeRuiter J, Abdel-Hay KM, Clark CR (2015) Mass spectral studies on 1-n-pentyl-3-(1-naphthoyl)indole (JWH-018), three deuterium-labeled analogues and the inverse isomer 1-naphthoyl-3-n-pentylindole. Rapid Commun Mass Spectrom 29:871-877

13. Glennon RA, Raghupathi R, Bartyzel P, Teitler M, Leonhardt S (1992) Binding of phenylalkylamine derivatives at 5-HT1C and
5-HT2 serotonin receptors: evidence for a lack of selectivity. J Med Chem 35:734-740

14. Aldous FAB, Barrass BC, Brewster K, Buxton DA, Green DM, Pinder RM, Rich P, Skeels M (1974) Structure-activity relationships in psychotomimetic phenylalkylamines. J Med Chem 17:1100-1111

15. Fuller RW, Baker JC, Perry KW, Molloy BB (1975) Comparison of 4-chloro-, 4-bromo- and 4-fluoroamphetamine in rats: drug levels in brain and effects on brain serotonin metabolism. Neuropharmacology 14:739-746

16. Harvey JA, McMaster SE, Fuller RW (1977) Comparison between the neurotoxic and serotonin-depleting effects of various halogenated derivatives of amphetamine in the rat. J Pharmacol Exp Ther 202:581-589

17. Harvey JA (1978) Neurotoxic action of halogenated amphetamines. Ann N Y Acad Sci 305:289-304

18. Leonard BE, Shallice SA (1971) Some neurochemical effects of amphetamine, methylamphetamine and $p$-bromomethylamphetamine in the rat. Br J Pharmacol 41:198-212

19. Juvancz P (1981) The effect of p-bromomethamphetamine (V111) on sleep in the rat. Eur J Pharm 70:461-466

20. Knoll J, Vizi ES (1970) Cross-tolerance between para-bromomethamphetamine (V-111) and LSD-25. Pharmacology 4:278-286

21. Knoll J, Vizi ES, Knoll B (1970) Pharmacological studies on para-bromo-methamphetamine (V-111) and LSD. Acta Physiol Acad Sci Hung 37:151-170

22. Hírlevél 2014/5. (http://drogfokuszpont.hu/wp-content/uploads/ NFP_hirlevel_2014_majus.pdf). Accessed 22 Jan 2015

23. DeRuiter J, Clark CR (1998) Gas chromatographic-mass spectrometric and high-performance liquid chromatographic analyses of the bromination products of the regioisomeric dimethoxyphenethylamines: differentiation of Nexus from five positional isomers. J Chromatogr Sci 36:23-28

24. DeRuiter J, Holston P, Clark CR (1998) Liquid chromatographic and mass spectral methods of identification for regioisomeric dimethoxyamphetamines and brominated dimethoxyamphetamines. J Chromatogr Sci 36:73-79

25. Taniguchi M, Yamamoto Y, Nishi K (2010) A technique combining trifluoroacetyl derivatization and gas chromatographymass spectrometry to distinguish methamphetamine and its 4-substituted analogs. J Mass Spectrom 45:1473-1476

26. Taniguchi M, Yamamoto Y, Nishi K (2013) Comparative in Vitro studies of the metabolism of six 4-substituted methamphetamines and their inhibition of cytochrome P450 2D6 by GC-MS with trifluoroacetyl derivatization. Am J Anal Chem 4:166-175

27. Westphal F, Rösner P, Junge Th (2010) Differentiation of regioisomeric ring-substituted fluorophenethylamines with product ion spectrometry. Forensic Sci Int 194:53-59

28. Negishi S, Nakazono Y, Iwata YT, Kanamori T, Tsujikawa K, Kuwayama K, Yamamuro T, Miyamoto K, Yamashita T, Kasuya F, Inoue H (2015) Differentiation of regioisomeric chloroamphetamine analogs using gas chromatography-chemical ionization-tandem mass spectrometry. Forensic Toxicol 33:338-347 